\title{
Facilitating Empowerment in Employees with Chronic Disease: Qualitative Analysis of the Process of Change
}

\author{
Inge Varekamp • Annelies Heutink • \\ Selma Landman · Cees E. M. Koning • \\ Gabe de Vries · Frank J. H. van Dijk
}

Published online: 7 July 2009

(c) The Author(s) 2009. This article is published with open access at Springerlink.com

\begin{abstract}
Introduction In the field of healthcare, empowering patients who have a chronic disease is defined as increasing their knowledge and skills, in order to enable them to define their treatment goals and take personal responsibility for their medical treatment. Our goal was to explore the nature of empowerment for employees who have a chronic disease and who experience work-related problems. Methods We used an explorative qualitative approach to document, from a professional perspective, the experiences of patients who participated in an empowerment training program. The researcher and the three instructors identified several themes which appeared to be important to many participants. These themes were finetuned and illustrated using brief case histories. Results We identified seven themes and characterized them in terms of employee tasks. These included: (1) developing a realistic understanding of one's abilities, (2) standing up for oneself in a self-confident way, (3) maintaining social relations based on mutual understanding with supervisors and colleagues, (4) collecting and assimilating knowledge of one's options, rights and duties, (5) consulting others and negotiating with regard to work accommodations, (6) planning
\end{abstract}

I. Varekamp $(\bowtie) \cdot$ F. J. H. van Dijk

Coronel Institute of Occupational Health, Academic Medical

Center, University of Amsterdam, P.O. Box 22600, 1100 DD

Amsterdam, The Netherlands

e-mail: i.varekamp@amc.nl

A. Heutink - C. E. M. Koning

Arbo Unie Occupational Health Service, Amsterdam,

The Netherlands

S. Landman · G. de Vries

Department of Psychiatry, Programme for Mood Disorders,

Academic Medical Center, University of Amsterdam,

Amsterdam, The Netherlands one's job so as to provide personal satisfaction, and (7) maintaining a social life outside work. Not every employee is faced with all of these tasks, but most have to deal with several. Conclusion Empowerment presupposes that employees with a chronic disease can act to solve problems at the workplace. The experiences during a comprehensive empowerment training illustrate that a process of reflection on personal emotions and a cognitive process of exploration and identification of bottlenecks at work may precede these actions. Our primary contribution is the aforementioned list of seven common tasks that many workers have to perform. Disseminating the list can support employees who have a chronic disease and may also be useful for their managers, HRM staff, occupational health and other healthcare workers.

Keywords Job retention - Chronic disease . Rehabilitation, vocational $\cdot$ Disability management .

Work disability · Employment · Workplace .

Job satisfaction - Occupational health · Return to work

\section{Introduction}

Many employees with a chronic disease manage their work well. However, many others are hampered in job performance and experience problems at work. Health complaints, physical or cognitive limitations, pain, fatigue or medical requirements may hinder the performance of specific work tasks or may even lead to work disability. The employment rate of persons with a chronic disease is, depending on the disease, slightly or considerably lower than for healthy persons. For instance, the majority of rheumatoid arthritis patients of working age in the USA and the Netherlands are employed (59 and 56\%) [1,2], and 
for inflammatory bowel disease or COPD the figures are roughly the same or even better [3-6]. More dramatic are the experiences of dialysis patients and people with Parkinson's disease or multiple sclerosis. Only $20-40 \%$ of them report being employed [7-10].

Yet, some employees with a chronic disease or handicap leave the labor market unnecessarily. Twenty percent of a large group of individuals with chronic diseases on incapacity retirement in the Netherlands judged their retirement unjustified [11]. Accommodations in the work place can be a solution to work-related problems and may prevent unnecessary sickness absence or job loss. In order for managers to implement appropriate accommodations it is necessary that employees understand their problems, discuss these with their supervisors or colleagues and reach a solution. This is not always easy. Recent research into the experiences of employees with rheumatoid arthritis, diabetes and hearing problems showed that it was critical for such individuals to accept their condition themselves, to have the support of their supervisor and to practice good coping strategies [12, 13].

We developed a vocational rehabilitation training program for employees with chronic diseases. These should be distinguished form other longstanding diseases. There are many longstanding common health problems, according to some responsible for 'about two-thirds of sickness absence, long-term incapacity and ill-health retirement' [14], that are essentially manageable, for instance with graded activity interventions or cognitive behavioral therapy. Non-specific low back pain is an example of such a common health problem. Chronic diseases are by definition diseases that do not go away. Apart from this permanency, other characteristics are unpredictability over time, day-to-day variability and often invisibility [15]. Although a clear distinction cannot always be made, it is important to discriminate between chronic diseases that are irreversible and mild or moderate cardio-respiratory, musculoskeletal or other longstanding but not necessarily irreversible conditions. Our group training program is designed for employees with a variety of serious chronic physical diseases who experience problems at work because of their medical condition. In contrast to a traditional approach in which an expert defines what the problem is and provides advice, we selected an 'empowerment' approach. The training supports the employees in clarifying barriers after which they are encouraged to develop solutions themselves. A literature review shows that, although a sound study design was often lacking, there exists moderate evidence for the effectiveness of empowerment-based interventions in terms of employment, implementation of work accommodations and psychological outcome measures [16].

Our training program offered us the possibility to achieve a better understanding of working with a chronic disease.
We could observe which problems employees actually encountered, how they discussed remedies in the group or with the trainer, how they practiced communication and negotiation with their supervisor or colleagues and reflected on that in the training group. Often, the participants reported how problems eventually were addressed at work. In this explorative study we try to understand what empowerment actually means for this group by describing from our professional perspectives the experiences of a significant number of participants. We have chosen to consider these experiences in terms of tasks. Not every employee is faced with all of these tasks but many have to deal with at least one, or more often several, of these. The tasks can be illustrated using brief case descriptions or case histories. We hope that our study will help employees as well as vocational rehabilitation professionals, supervisors and HRM professionals to recognize and solve work-related problems.

Preceding the results we will discuss developments in empowerment theory, the set-up and contents of the training, and the methods used in this study. Our results section begins with one elaborate case history that illustrates how different tasks can be interrelated. This study is part of a larger research project which includes a randomized controlled effectiveness study.

\section{Empowerment of Employees with a Chronic Disease}

Empowerment was first explored in the 1980s in community psychology as a means of enabling individuals to gain decision making power within their community. Empowerment was seen as a multilevel construct through which individuals, groups, organizations, the community, and social policy are seen as mutually influential [17]. More recent research agendas have distinguished various empowerment processes and outcome measures at the level of the individual, the group and the community [18].

The word 'empowerment' was adopted in healthcare, notably in the management of chronic diseases, under the full term 'patient empowerment'. Patient empowerment is defined as a process to help patients develop knowledge, skills and a heightened awareness of values and needs. In turn, this enables them to define their goals, take responsibility for their medical treatment and increase their autonomy. This definition implies improved problem solving abilities, better communication with healthcare professionals, and often an awareness of health-promoting behaviors [19]. Empowerment-oriented interventions based on this definition focus on attitudes, knowledge, skills and behavior without reference to social inequality or society at large.

The term empowerment asks for some special considerations when using it with respect to the labor market and in occupational health. There are no fundamental conflicts of interest between healthcare providers and healthcare 
consumers. Basically both parties see effective medical treatment as a primary goal, although patients may find themselves in an unequal power relationship with healthcare professionals, due to the professional autonomy of this group [20]. Social relations in the labor market, however, are different from those in healthcare, which requires a careful interpretation of the empowerment concept. Employers and employees have shared as well as conflicting interests, which can become problematic in the case of employees with health problems. Both parties benefit from good interpersonal relations in which employees perform optimally. Conflicting interests arise when employers and supervisors aim for a high level of labor productivity and consequently a high workload, whereas employees with a diminished work capacity strive for a lower workload. In everyday reality employees with a chronic disease are confronted with a wide variety of attitudes and actions from employers, line managers, supervisors and HRM-professionals. Employees may even notice management struggling with conflicting interests and ethical considerations. Some will experience support in their striving to keep employed, while others are confronted with a wish to maximize production and minimize costs. These potentially conflicting interests demand an interpretation of the concept of empowerment that is not limited to intrapersonal aspects. A critical awareness of the sociopolitical context must be integrated to fully appreciate empowerment [21]. The empowerment of individual employees will be useless if the government and employers' organizations ignore or disrespect employees with health problems [22].

\section{A Short Description of the Setup and Content of the Training Program}

The training focuses on solving work-related problems and aims at maintaining or increasing work satisfaction and job retention. A stepwise approach is used, first exploring and clarifying work-related problems, second focusing on communication at work, and third developing and realizing solutions.

The group training sessions involve one instructor and eight participants. There are six 3-h sessions every 2 weeks and a seventh session 2 months after the sixth session. To discuss personal problems or to elaborate issues, there are three individual consultations, one at the beginning, one halfway the training course, and one after the sixth session. A textbook accompanies the course and participants must prepare homework for every session. Each session has a theme:

1. Exploration of practical and psychosocial problems according to the 'Quality of work' model (Fig. 1).
Energy sinks and energy sources

\begin{tabular}{|l|}
\hline Burden and task content \\
- physical load (too high or too low) \\
- mental stress (too high or too low) \\
$\cdot$ emotional stress \\
$\cdot$ general work stress (too high or too low) \\
- uncertainty about tasks and responsibilities \\
- disruption at work
\end{tabular}

\begin{tabular}{|l|}
\hline Work autonomy \\
$\cdot$ planning tasks oneself (insufficient autonomy \\
or too much) \\
$\cdot$ deciding on break times \\
$\cdot$ determining work hours \\
\hline
\end{tabular}

\begin{tabular}{|l|}
\hline Relationships at work \\
- feeling appreciated at work \\
- support of line management or supervisor \\
- support of colleagues \\
- social atmosphere at work \\
\hline
\end{tabular}

\begin{tabular}{|l|}
\hline Suitable terms of employment \\
$\cdot$ fit into the organization \\
$\cdot$ job certainty \\
$\cdot$ payment in accordance with performance \\
\hline
\end{tabular}

\begin{tabular}{|l|}
\hline Work-home interference \\
$\cdot$ problematic home life \\
$\cdot$ commuting \\
$\cdot$ leisure activities \\
\hline
\end{tabular}

Fig. 1 (simplified) The 'quality of work' model

2. Insight into feelings and thoughts about having a chronic disease.

3. Communication in everyday work situations: role play part one.

4. Practical matters; the occupational physician, the employment expert, legislation and facilities for disabled employees.

5. Communication and standing up for oneself: role play part two.

6. Solving problems.

7. Follow-up: what works and what does not?

A comprehensive description of the development, setup and content of the training course is published elsewhere [23]. 


\section{Methods}

Eight groups of eight participants each were enrolled in our training courses. The researcher (IV) attended the first two training courses and the preceding pilot training course and reported her observations. The instructors $(\mathrm{AH}, \mathrm{SL}$, CEMK) filled in a process evaluation form after each group session and made notes after each individual consultation.

Shortly after the beginning of the project, the researcher asked the instructors to make notes about cases they deemed relevant. The criterion for relevancy was that the case illustrated how participants dealt with work-related problems. An initial listing of several case histories let us identify recurring themes. These themes can be understood in terms of 'tasks that have to be performed' by the employees. The researcher discussed a classification of six tasks with each of the instructors individually. This resulted in additions, amendments, and further case histories. All the authors collaborated in a consensus meeting to arrive at the next version, which featured seven tasks. The result was a more precise description of the tasks and brief case histories. The final version was revised and commented on by all the co-authors; if necessary, case histories were added. Cases were de-identified by changing personal characteristics in order to respect privacy.

\section{Results}

Marian is 53 years old and has suffered from rheumatoid arthritis for 20 years. She has a full-time administrative job at the distribution center of a supermarket chain. Fatigue and pain are frequently troubling her. Her predominant attitude is: 'I refuse to accept my medical condition; I want to do my job the way I used to do it.' Sometimes she feels her coworkers do not understand her condition. In her opinion the fact that her condition is not visible contributes to negative perceptions among her coworkers. In addition to an $8 \mathrm{~h}$ working day, Marian commutes $3 \mathrm{~h}$ a day. In the end she feels overburdened.

Her occupational physician has advised that Marian try to transfer to an establishment of the company in her place of residence. She talks with the line manager of this establishment, but this does not sound promising; he seems to hint that Marian may not be very productive given her health status. He does agree to forward Marian's case to a hiring committee for a second opinion. They will probably offer Marian a 6-month trial transfer. Marian is afraid that she will not get a fair chance because of the skepticism of the line manager right from the beginning. She is afraid that she may have to return to her current workplace after 6 months. By that time, others will have taken over her job, and than she is even more in a mess.

She is angry: 'I have worked hard for 30 years and have always received good performance evaluations. Now I am facing difficulties and they let me down.'

What does empowerment mean in this case? First of all, Marian realizes that she has to change her attitude toward her disease: 'I will have to accept that my work capacity is lower'. Furthermore, she has set herself two targets. She wants to learn how to explain her disease to others and she wants to prepare a transfer proposal case. Using a role play situation, she practices telling a new colleague about her rheumatoid arthritis and what its consequences are at work. She explains that sometimes she feels very fatigued. When colleagues ask her to pay attention, she can request a few minutes of personal time. She explains that although she may be quiet when she is exhausted, this does not mean that she is angry with her coworkers. After the role play, Marian becomes emotional and she remarks that she found the exercise exhausting. Her role play partner tells her that, as a colleague, he would appreciate understanding her medical problems. Then she practices a consultation with a line manager in which she asks for permission to explain the consequences of her disease to colleagues during a group meeting. The first time she is put off by the role play partner (line manager): 'Okay, you can just go round to everybody individually.' But this is not what Marian wants. She does not want to have to recount her story ten times and risk becoming emotionally worn out. The other participants in our training session encourage her, by telling Marian 'You shouldn't let your line manager boss you around'. The second time she is more forceful with her 'manager' and he agrees to her proposal to speak to her colleagues all at the same moment.

Marian's second and most important target is the upcoming discussion about transferring to a new workplace that is closer to where she lives. The participants discuss how Marian should tackle this problem. The instructor recommends: 'Feel strong and focus on what you want to achieve, which is to get a transfer.' Another participant remarks: 'Whose problem is this anyhow, yours or your manager's?' This comment reflects the sense of guilt that many participants often feel about their inability to perform certain types of work. The employment expert gives her this piece of advice: 'If you are to be assessed in 6 months' time, you should find out right now what the assessment criteria are. Otherwise they may surprise you.'

Two weeks later Marian recounts how she felt confident about the actual discussion with the hiring committee, including the new line manager. 'I was 
determined and forthright.' She told the manager that she did not need 6 months to prove herself, and that she could do it in 2 months. However, she did agree to give up some administrative tasks and she will lose some of her salary. This change of tasks was actually one of Marian's requests, so that she would have more energy. Also, she has asked for a follow-up evaluation with the line manager after 2 months. At that time she plans to verify whether her expectations are aligned with the line manager's expectations.

Two months later Marian gives her training group an update. She likes her new workplace, especially because it is so close to home. She has more leisure time, goes to a fitness center and she enjoys every day. She has consulted the occupational physician about what work accommodations may be appropriate for her and she was surprised to find out that she could have whatever accommodations she felt she needed to be able to work effectively. In the beginning she was very worried about her 6-month probationary period, but she is now much more relaxed about it. To date her new line manager has not asked Marian how she is getting on. However, more senior managers have expressed interested in how she is doing. In the last counseling session the instructor advises her to contact the HR department about her case. Four months later, Marian informs us that she has been given permission to stay.

\section{Seven Tasks that Employees with a Chronic Disease Often Have to Deal with}

\section{To Develop a Realistic Understanding of One's Abilities}

If one wants to solve problems, first of all it is necessary to understand both one's limitations and possibilities. Questions to answer include 'where am I now' and 'what do I want,' in terms of one's career and one's life. Many participants experienced their job as one big tangle of stress and problems. Implicit but predominant negative thoughts were: 'I achieve less than my coworkers' or 'There is no point in trying to change things'.

The 'Quality of Work' model helped participants to understand their problems. Just as important was listening to others in the training group. They often heard stories that resonated with their own experiences. Our sessions led certain participants to realize that denial, anger or feelings of guilt were still present even though they believed that they had more or less had come to terms with their chronic disease. Recognizing these emotions helped them move forward in a grieving process. This was an important first step in considering the consequences of their disease and in accepting that they may need accommodations at the workplace.

Martin is 38 years old and has become seriously visually handicapped over the past 8 years. He uses a software-based screen magnifier for his computer. He finds computer use fatiguing. Usually he is completely exhausted at the end of each day. Nevertheless, he avoids talking about his handicap and he is inclined to think: 'My problem is not very major, I cannot complain.'

The others' narratives encourage him to admit that he routinely denies his handicap. Martin decides to discuss his condition with his supervisor.

George is a 38 year old psychiatric nurse. Seven years ago he was diagnosed with Crohn's disease and was away from work for an extended period. Two years ago he got depressed. Since then he has felt that he is a failure in life. He feels that his supervisor sees him as a failure too, and does not respect him.

Through the help of the 'Quality of Work' model and by listening to the others in the training group, George learns to accept his limitations and he develops a realistic perspective. He puts it aptly: 'I have to reinvent my life.' He decides to apply for a job elsewhere, which he gets.

\section{To Stand Up for Oneself in a Self-Confident Way}

Successfully negotiating special needs accommodations at work requires self-respect which is the first step in developing self confidence attitude.

Some participants experienced feelings of sadness, anger or shame, or thought that they were less valued than their coworkers. This sometimes made them avoid their supervisor. They often passively did what they were told and they were easily overruled by their colleagues.

Listening to others and telling their own stories helped some participants realize that they were less assertive than they thought they were. Discussing work situations helped them realize that they sometimes failed in clear communication. Role play exercises showed them other ways to approach situations. They began to understand how they could influence situations by becoming more self-reliant and assertive.

John is a 46 year old ICT-worker. He has chronic obstructive pulmonary disease (COPD) for over 10 years. 'It feels like I run a marathon every day.' His subconscious thought about his performance at work is that he is an underachiever. 'Thinking something like that makes you start avoiding other people, which in 
turn causes stress' he says. The consequence was that he would work beyond his capacity, and would be fatigued all the time. He lost his job after a clash with his line manager. Now he works elsewhere on probation.

Through talking about his problems and experiences, John gains an understanding of his feelings and thoughts in respect of his disease. In his new job he does not avoid the line manager and his colleagues and he tries to set realistic work goals given his condition.

Charlotte is 52 years old and has a heart condition. She qualifies for a partial (25-35\%) work disability pension and works part time as a domestic servant in a home for the elderly. She says: 'My work performance is below par, so I never talk to my supervisor.' She avoids contact with this woman. At the same time she is upset about the situation and she would like to rearrange her work in a more satisfying way.

During a role play scenario, she practices how to confidently start a conversation with her superior. The first time she asks timidly whether her 'superior' possibly has time to talk with her and she immediately hears excuses. The second time she clearly articulates what she needs and she secures a meeting with her supervisor to talk about her difficulties.

3. To Maintain Social Relations with Supervisors and Colleagues on the Basis of a Mutual Understanding

Employees interact with others. Their supervisor assigns tasks and they work on those tasks together with their colleagues. Cooperation is more than simply performing an activity with someone else. It requires being on good terms with others and promoting a good mutual understanding.

Some participants felt they were misunderstood at the workplace, especially if their disease was invisible. When they felt that this negatively impacted social relations, this caused feelings of insecurity and frustration.

They learned that others at the workplace are more likely to be understanding when the disease and its consequences in terms of pain, fatigue, physical or cognitive limitations or medical requirements are explained to them. They also noticed that they themselves may misjudge their colleagues' intentions. They were inclined to interpret a colleague's sullen behavior as rejection, although the colleague may very well have been grumpy for an entirely different reason. They learned how important it was to validate these assumptions.

Evelyn is a 45 year old employee at a post office. She is less productive than her coworkers, due to Parkinson's disease. Her workload has been modified due to her condition, but she notices that this has made some of her colleagues irritated. She realizes that not everybody understands her health problems.

She uses role play to explain the consequences of Parkinson's disease at work. Then she explains these issues to her colleagues in real life. Since then they tend to ask her how she is doing more often.

Gertrude is 48 years old and suffers from Sjögren's syndrome. She used to get on well with her colleague Mary. Since her illness, she has felt rejected by Mary which gives her wretched feelings.

During the training sessions, Gertrude realizes that she might be mistaken and she is encouraged to talk things through with Mary in person. Because of this, the tension between them disappears and they discuss how their misunderstanding may have come about.

4. To Collect and Assimilate Knowledge of One's Possibilities, Rights and Duties

Physical or cognitive limitations lead to reduced ability to work. Special accommodations at work aim to prevent overburdening by reducing work tasks or improving an individual's work capacity. Sickness absence and work disability legislation all deal with these issues as well. Legislation requires that employees inform themselves about special needs accommodations at work, the financial arrangements involved and their legal rights and duties.

Participants in our sessions often realized that they were insufficiently well informed in this regard. For instance, they did not know that it is usually possible to visit an occupational physician for advice, even without a referral. Or that Dutch sickness absence legislation requires the employer to cooperate with the employee to formulate a back-to-work plan in cases of long term absence. This means that the employee himself must also be actively involved in the process. Some participants were worried about their financial needs and were not familiar with Dutch incapacity benefits legislation. In short, participants often did not know what steps they could take themselves. They ended up being too passive and simultaneously became frustrated because of the lack of progress.

In the training sessions, their problems at work served as a starting point to acquire specific knowledge about their options given the government's legislation. This information encouraged them to consider their options more fully. For instance, new ideas and initiatives included encouragement to explore special needs accommodations at work, incapacity benefit regulations or the possibility of a different type of job with their current employer or with a new employer. 
Steven is 32 years old and is employed at a small software company. He has Crohn's disease for the past 5 years and he is often on sick leave. He feels that he keeps letting his employer down. Moreover, he misses out on annual pay rises and he receives no bonus for unused sick days. At the same time he thinks: 'At least I have a job, who else would employ me given my disease?'

Steven is a family breadwinner and the financial aspects of his role are very important. He asks the employment specialist about partial work disability and partial incapacity benefits. He gets a clear idea of his options and decides to find a better paid job elsewhere and work fewer hours a week.

Grace is a 46 year old editor who has had rheumatoid arthritis for the past 7 years. She is overworked; 10 or $20 \mathrm{~h}$ of overtime is normal at her publishing company. She feels that her colleagues will see her as ill-qualified for her job if she does not accept the long hours.

During our sessions, Grace asks the occupational physician and employment expert how she can request less overtime from her employer. At the end of the training sessions, she knows her rights as stated in sickness absence legislation, and she understands what responsibilities her employer has in her case.

\section{To Consult Others and Negotiate Work Accommodations}

When employees have identified the bottlenecks at work and have some idea about the kind of arrangements they would need, the next step involves consulting others, negotiating with supervisors and standing up for one's rights.

Participants sometimes waited for things to happen and would become frustrated when nothing came about. When they themselves took action, they found it difficult to discuss their limitations and to properly articulate problems which they would normally minimize, out of habit. When they talked to their supervisors and nothing happened, they got all the more frustrated. They were inclined to see their problems as problems they were responsible for. They were often too concerned about the supervisor's interests and convinced that there was no good answer to their problems. Sometimes they felt they needed to devise a plan alone, instead of working with the supervisor to develop a strategy collaboratively.

They learned that they should make their problem a joint problem and address it piecemeal. By doing this they can keep the issue on their supervisor's radar.
Ingrid is 43 years old and enjoys her job as a university researcher. She has MS and uses a wheelchair. She needs several practical work accommodations, like a more spacious place to work on the ground floor, a disabled toilet, accessible furniture and a personal printer. Some accommodations can be readily addressed, others will take time. However, Ingrid acts as though she does not need special accommodations because she does not want to inconvenience others. She says to technical support personnel that there is no hurry to install a new desk: 'I'm managing just fine, I can wait.' She does this even though it causes her significant inconvenience to make do with an unsuitable work environment. The large room that she would need on the ground floor would require a colleague being moved to a smaller room. This troubles her.

She learns that she should not be concerned about her colleague; that is an issue between her colleague and her supervisor. She learns to keep reminding her supervisor until the alterations have been completed. Ultimately she ends up feeling like a valued member of the department again.

Louise is a 47 year old employee at a primary school. She has developed renal insufficiency in the past 5 years and she works long hours. She does not want to ask for a workload reduction because she thinks that it may burden her colleagues.

She learns to specify clearly that she can no longer manage her work hours and articulate the consequences for her task load and her schedule. She is surprised to find that it is possible to adapt both her task load and schedule.

\section{To Organize One's Job in a Way that it Still Gives Satisfaction}

A job offers income, status, social relationships and a defined structure for both each day and each week. Furthermore, it offers self-fulfillment. People flourish and have energy when their work gives them satisfaction. This does not hold true for everything that one does at work, but there should be a sufficient number of energizing tasks.

Some participants stated that, because of their chronic disease, they were relieved from their tasks to such a degree that the real challenge was gone. Others had changed for a physically less demanding job and found that it ultimately did not satisfy them.

They learned to recognize that this was the real problem. Their tasks needed to be adapted to their skills or they had to find another job that they liked, either with their current employer or with a new employer. 
Elisabeth has arthrosis and Crohn's disease. She works as a secretary and is in a back-to-work program after a burnout. The incapacity benefits agency has advised her to cut down from $4 \times 8 \mathrm{~h}$ a week to $4 \times 6 \mathrm{~h}$ a week. However, this increases her stress because she tries to do the same amount of work in fewer hours.

She has agreed with her husband that she will work $4 \times 8 \mathrm{~h}$ and he will do more household chores. She has given up some of her less enjoyable work tasks and has taken on more organizational tasks that she does enjoy.

Patricia is a 43 year old woman who has Ménière's disease for the past 6 years. She used to enjoy her job as a medical receptionist. Her neurologist advised her 5 years ago to find a part time job as a secretary. However, she does not like her new work at all and she finds it mentally draining to go to the office each day.

The training sessions helps her realize that she could have continued her old job, notwithstanding her physical limitations. She starts applying and finds a part-time job in her former occupation.

\section{To Maintain a Social Life Outside Work}

People need social lives outside work, complete with leisure activities and social relationships. This offers the opportunity to recover from fatigue and become re-energized.

Some participants felt that continuing with their current job required so much energy that housekeeping, leisure activities and social relationships were severely affected. As a consequence, life became even harder. One individual in our program became socially isolated.

We recommended giving a higher priority to their nonwork time instead of clinging to their job at the cost of everything else. This made it possible for some participants to escape the downward spiral.

Marit is a 34 year old fundraiser with very poor eyesight. Although the loves her job, she experiences significant stress at work and she is often exhausted at the end of the day.

The training forces her to think about what she really wants. She wants to be more relaxed in her job and her private life. She starts trying out various leisure activities that will give her energy.

Bernard is a 57 year old divorced school teacher. He has HIV and has never really come to terms with it; nobody knows, not even his children. Contact with his colleagues and with the principal is poor and he feels like burnt out. Besides, he is socially isolated and has started to neglect household chores.

He has feelings of shame and sadness about his disease, but he realizes that he is not the only one in the group who feels depressed on account of his disease. This wakes Bernard up to think about his situation and make choices. Little by little he starts to understand that he allowed his colleagues to intimidate him as a result of his feelings of shame. This is the reason for his exhaustion and social isolation. He starts to connect with others in his private life and resumes contact with children and friends.

\section{Discussion}

The aim of our study was to show how employees with a chronic disease participating in an empowerment training program experience their work-related problems and how they learn to manage these. We articulated three steps in advance of the program: clarification of problems, communication and problem solving. The efforts to clarify and manage the problems can be formulated in terms of themes or tasks: (1) developing a realistic understanding of one's abilities; (2) standing up for oneself self-confidently; (3) maintaining social relations based on mutual understanding; (4) acquiring knowledge of one's options, rights and duties; (5) negotiating with regard to work accommodations; (6) planning one's job so as to provide personal satisfaction; and (7) maintaining a social life outside work. Not every employee in the training was faced with all of these tasks, but most had to deal with several.

Our study is an explorative qualitative study. It offers, from a professional point of view, insight into the problems that individuals encounter and the processes they go through. It is clear that employees experience various difficulties, depending on the nature of their disease, work requirements, atmosphere at work and personality. Our conclusions are based on a large amount of data. They consist of observations from the researcher and the three instructors, who led eight training groups and an additional pilot training group. These included 72 employees. In addition, all the instructors conducted three individual counseling sessions with each participant. In total, our conclusions are based on our experience with 62 group sessions and 197 individual consultations.

Our study has several limitations. We studied how employees resolved problems using techniques learned in our specific intervention program. The nature of the intervention may have limited the number of tasks people report that they are confronted with. Our empowerment-based training program focused on clarification, communication 
and problem-solving. A different kind of intervention might have revealed other important aspects. Another limitation of the study is that it is based on the instructors' and researcher's perspectives. There were only a few dropouts in the training programs and the average evaluation of the program was 8.1 (scale 1-10). Especially topics like 'Insight into yourself: feelings and thoughts about having a chronic disease' and 'Communication and standing up for oneself' scored high in the evaluation of the participants. However, notwithstanding the satisfaction of the participants with the program, the instructors' and researcher's perspectives might be biased.

How do the results of this study compare to other studies? Healthcare best practices for patients with chronic diseases concentrate on supporting individuals in selfmanaging their disease. A number of effectiveness studies have been published regarding self-management training and related interventions based on psychosocial theories of health behavior (e.g. [24-27]). These studies are usually restricted to measuring attitudes, skills and knowledge or describing process variables and the nature of the intervention. The actual processes that individuals undergo and their changing perspectives are rarely discussed. Qualitative medico sociological research offers a view that is better aligned with our findings. In his sociological and autobiographical retrospective on living with cancer, Nijhof [28] describes individuals who are confronted with a chronic disease as persons who set foot on unfamiliar territory: 'What does this disease mean? Which things can I still do, and which can I no longer do?' Also, what they will tell others and how they will tell them becomes an issue. 'Will they believe it? Or will they think that it is not really serious, or even more serious?' Nijhof names this searching for a path through an unfamiliar territory 'work.' He joins Strauss and Corbin [29] who speak about 'trajectory work' in their research. Individuals experience an incurable disease as a series of phases: acute or less acute change, recovery, stability, instability and possibly deterioration. The disease is not something that happens to people, but something that needs to be managed: one tries to control its course, to treat symptoms, and to live with the resulting limitations. Most of the time people cannot manage on their own. They need to make arrangements with the help of others, and every new phase demands readjustment. In addition to this 'practical' work, a serious chronic disease requires 'biographical' work. The disease disrupts individual biographies and individuals are faced with the task of redefining their identity and that of their next of kin. Charmaz [30], who performed many in-depth interviews with chronic diseased in the US, speaks of a 'loss of self'; the image that people had of themselves and which is linked to American values of freedom and independence gets lost. This loss might get even worse when physical limitations prevent people going out, when they lose social connections and get dependent from others.

The aforementioned studies do not address the combination of chronic disease and employment, maybe because many individuals with a chronic disease already have lost their jobs. Nevertheless, there are many analogies with our study. Employees with a chronic disease see themselves as being burdened with all kinds of practical 'work': discussing work-related problems, figuring out their options, standing up for their rights, and maintaining social relationships. Notably, biographical work deserves attention. It turns out that employees with a chronic disease see themselves as underachievers, with accompanying feelings of worthlessness. One of the participants expressed this aptly by saying: 'One has to re-invent oneself.' These findings are also consistent with a qualitative study on rehabilitation programs for women with chronic musculoskeletal pain [31]. These women found the process in which they regained their selfrespect the most valuable contribution to their recovery.

What are the practical implications of this study? We identified a number of recurring themes which presumably are all relevant for at least a number of employees with a chronic disease. We illustrated these themes with cases in their actual social context. These themes and brief case studies may clarify for employees what problems they face and how they can address these issues. For instance, one of the most important tasks that employees face turns out to be communication with others, in order to request accommodations at work. When employees learn why communication can be difficult and how it can be improved, this can be very helpful to their work life.

The findings of this study are also relevant for "the other party' involved. Employers and managers need to know what concerns employees who have a chronic disease. Unpredictability over time, day-to-day variability, permanence, and invisibility are relevant characteristics of chronic diseases [15]. The themes identified illustrate what it means for employees to have to cope with these aspects of chronic disease. These require a flexible and compassionate employer attitude which should include openmindedness as to the diversity of this group [15]. They wish to be judged not only on their limitations but also on their qualities. They also want recognition for the importance of a job that they do wholeheartedly and that gives them satisfaction.

We advocate policies aimed at job retention for employees with a chronic disease, and for the corresponding attention of employers, HRM-departments and occupational health services. Employers have to issue a clear mission and vision for their company and they have to provide positive support to those supervisors and line managers who need help understanding and managing these issues. One important task, for which they might need 
assistance, is to communicate openly with their employees about job limitations and mutual expectations. When employers and society at large are aware of these requirements, empowerment may lead to a 'multilevel' interpretation, encompassing individuals, companies, professional associations and social policy.

In order to reach a more comprehensive understanding of working with a chronic disease, more research is needed on the process of completing 'tasks,' for instance in respect of which factors are stimulating and which are hindering. We need to learn more about the experiences of colleagues, supervisors, HRM-personnel and occupational physicians.

In conclusion, in many cases it is possible to work with a chronic disease. But it is challenging. Individuals may experience uncertainty, physical, cognitive or emotional limitations, and medical treatment may interfere. All of these issues must be thought through, addressed and accepted. Then the problems must be made compatible with a regular workday. Employees themselves and others at the workplace should realize that this requires effort from all sides. This exploratory study identifies tasks that many employees with a chronic disease may be confronted with. Knowledge about these tasks may help better support employees and stakeholders to communicate and find solutions.

Acknowledgments The development and realization of the intervention as well as the study are financially supported by the Dutch Ministry of Social Affairs and Employment and GAK Institute Foundation (Stichting Instituut GAK). The occupational health service provider ArboUnie supported the development and realization of the intervention.

Competing interests The authors declare that they have no competing interests.

Open Access This article is distributed under the terms of the Creative Commons Attribution Noncommercial License which permits any noncommercial use, distribution, and reproduction in any medium, provided the original author(s) and source are credited.

\section{References}

1. Allaire S, Wolfe F, Niu J, Lavalley MP. Contemporary prevalence and incidence of work disability associated with rheumatoid arthritis in the US. Arthritis Rheum. 2008;59(4):474-80.

2. Verstappen SM, Boonen A, Bijlsma JW, Buskens E, Verkleij H, Schenk Y, et al. Working status among Dutch patients with rheumatoid arthritis: work disability and working conditions. Rheumatology (Oxford). 2005;44(2):202-6.

3. Feagan BG, Bala M, Yan S, Olson A, Hanauer S. Unemployment and disability in patients with moderately to severely active Crohn's disease. J Clin Gastroenterol. 2005;39(5):390-5.

4. Longobardi T, Jacobs P, Bernstein CN. Work losses related to inflammatory bowel disease in the United States: results from the National Health Interview Survey. Am J Gastroenterol. 2003;98(5):1064-72.
5. Longobardi T, Jacobs $\mathrm{P}, \mathrm{Wu} \mathrm{L}$, Bernstein CN. Work losses related to inflammatory bowel disease in Canada: results from a National Population Health Survey. Am J Gastroenterol. 2003;98(4):844-9.

6. Kremer AM, Pal TM, van Keimpema AR. Employment and disability for work in patients with COPD: a cross-sectional study among Dutch patients. Int Arch Occup Environ Health. 2006;80(1):78-86.

7. Kutner N, Bowles T, Zhang R, Huang Y, Pastan S. Dialysis facility characteristics and variation in employment rates: a national study. Clin J Am Soc Nephrol. 2008;3(1):111-6.

8. Banks P, Lawrence M. The Disability Discrimination Act, a necessary, but not sufficient safeguard for people with progressive conditions in the workplace? The experiences of younger people with Parkinson's disease. Disabil Rehabil. 2006;28(1): $13-24$.

9. Martikainen KK, Luukkaala TH, Marttila RJ. Parkinson's disease and working capacity. Mov Disord. 2006;21(12):2187-91.

10. Pompeii LA, Moon SD, McCrory DC. Measures of physical and cognitive function and work status among individuals with multiple sclerosis: a review of the literature. J Occup Rehabil. 2005;15(1):69-84.

11. Nivel, Factsheet PPCZ. Chronisch zieken en de nieuwe WAOplannen. Utrecht: Nivel; 2002.

12. Detaille SI, Haafkens JA, Van Dijk FJH. What employees with rheumatoid arthritis, diabetes mellitus and hearing loss need to cope at work. Scand J Work Environ Health. 2003;29:134-42.

13. Varekamp I, Haafkens JA, Detaille SI, Tak PP, van Dijk FJ. Preventing work disability among employees with rheumatoid arthritis: what medical professionals can learn from the patients' perspective. Arthritis Rheum. 2005;53(6):965-72.

14. Waddell G, Burton AK, Kendall NAS. Vocational rehabilitation. What works, for whom, and when?. London: TSO; 2008.

15. Beatty JA, Joffe R. An overlooked dimension of diversity: the career effects of chronic illness. Organ Dyn. 2006;35:182-95.

16. Varekamp I, Verbeek JH, van Dijk FJ. How can we help employees with chronic diseases to stay at work? A review of interventions aimed at job retention and based on an empowerment perspective. Int Arch Occup Environ Health. 2006; 80(2):87-97.

17. Rappaport J. Terms of empowerment/exemplars of prevention: toward a theory for community psychology. Am J Community Psychol. 1987;15(2):121-48.

18. Perkins DD, Zimmerman MA. Empowerment theory, research, and application. Am J Community Psychol. 1995;23(5):569-79.

19. Feste C, Anderson RM. Empowerment: from philosophy to practice. Patient Educ Couns. 1995;26(1-3):139-44.

20. Johnson TJ. Professions and power. London: The Macmillan Press Ltd; 1979.

21. Zimmerman MA, Warschausky S. Empowerment theory for rehabilitation research: conceptual and methodological issues. Rehabil Psychol. 1998;43:3-16.

22. Palmer CD. Self-advocacy among people with disabilities in the transition from good will to civil rights: Is it sufficient? Work. 2000;14(1):61-5.

23. Varekamp I, de Vries G, Heutink A, van Dijk FJ. Empowering employees with chronic diseases; development of an intervention aimed at job retention and design of a randomised controlled trial. BMC Health Serv Res. 2008;8:224.

24. Anderson RM, Funnell MM, Butler PM, Arnold MS, Fitzgerald JT, Feste CC. Patient empowerment. Results of a randomized controlled trial. Diabetes Care. 1995;18(7):943-9.

25. Taal E. Self-efficacy, self-management and patient education in rheumatoid arthritis. Ph D thesis. Delft: Eburon; 1995.

26. Schreurs KMG, Colland VT, Kuijer RG, De Ridder DTD, Van Elderen Th. Development, content, and process evaluation of a 
short self-management intervention in patients with chronic diseases requiring self-care behaviours. Patient Educ Couns. 2003;51(2):133-41.

27. Landsman-Dijkstra JJA. Building an effective short healthpromotion intervention. $\mathrm{Ph} \mathrm{D}$ thesis. Hasselt: Drukkerij Schuttersmagazijn bv; 2005.

28. Nijhof G. Ziekenwerk; Een kleine sociologie van alledaags ziekenleven (Illness work; a small sociology of everyday illness life). Amsterdam: Aksant; 2002.
29. Strauss A, Corbin JM. Shaping a new health care system: the explosion of chronic illness as a catalyst for change. San Francisco: Jossey-Bass Publishers; 1988.

30. Charmaz K. Loss of self: a fundamental form of suffering in the chronically ill. Sociol Health Illn. 1983;5(2):168-95.

31. Gustafsson M, Ekholm J, Ohman A. From shame to respect: musculoskeletal pain patients' experience of a rehabilitation programme, a qualitative study. J Rehabil Med. 2004;36(3): 97-103. 